\title{
IMPLEMENTASI LUKISAN KLASIK KAMASAN PADA MEDIA ALTERNATIF TENGKORAK KEPALA KERBAU
}

\author{
I Gede Arya Sucitra \\ (Jurusan Seni Murni, Fakultas Seni Rupa, ISI Yogyakarta, arya.sucitra@isi.ac.id, 083867072303)
}

\begin{abstract}
In making a contemporary work of art, takes creativity and awareness of locality values, traditional visual elements by taking a visualization of the past and present in socio-cultural discourse. The material object of the creation of this painting will develop the decorative elements of the Kamasan classical painting of Balinese tradition, with exploration in an alternative medium of fine art that is using three-dimensional of an organic object media, is buffalo skulls. The representations of works tend to be ornamental, adapting the character of shapes, and the philosophical content of Classical Kamasan paintings. Strategies for developing ornamental designs are carried out as part of adaptation to the development of global art. The Intrinsic ornamental variety development model that emphasizes of distillation, transformed, distorted and develops ornamental variety with extrinsic powers, namely the value of meaning or symbolic. The implementation of elements of tradition with alternative art media becomes part of the dynamics of cultural development that has the opportunity to process, change, enrich and transform the work of art in accordance with the times. Visualization of this tradition often appears in the visual form of signs or markers in contemporary art. The exploration and implementation of the Kamasan Classic Balinese painting with buffalo skull is expected to provide an enrichment of the visuality of traditional artifacts in Indonesian contemporary paintings.

Keywords: Contemporary Art, Tradition, Alternative Media, Kamasan Painting.
\end{abstract}

\begin{abstract}
ABSTRAK
Dalam pembuatan suatu karya seni kontemporer dibutuhkan suatu kreativitas dan kesadaran akan nilainilai lokalitas, elemen visual tradisional dengan mengambil visualisasi masa lalu dan masa kini dalam wacana sosial budaya. Objek material penciptaan lukisan ini akan mengembangkan unsur dekoratif dari lukisan tradisi klasik Bali Kamasan, dengan eksplorasi pelukisan pada media alternatif seni rupa yakni menggunakan media objek tiga dimensi organik yakni tengkorak kepala kerbau. Representasi karya cenderung bercorak ornamentik, mengadaptasi karakter bentuk, dan kandungan filosofis dari lukisan Klasik Kamasan. Strategi pengembangan ragam hias dilakukan sebagai bagian adaptasi terhadap perkembangan seni rupa global. Model pengembangan ragam hias secara Intrinsik lebih mengedepankan pada proses distilasi, ditransformasi, didistorsi maupun mengembangkan ragam hias dengan kekuatan ekstrinsik yaitu nilai makna atau simbolis. Implementasi elemen tradisi dengan media seni alternatif menjadi bagian dinamika perkembangan kebudayaan yang berpeluang untuk mengolah, merubah, memperkaya maupun proses transformasi karya seni sesuai dengan perkembangan zaman. Visualisasi tradisi ini seringkali muncul dalam bentuk visual tanda-tanda ataupun penanda pada karya-karya seni kontemporer. Eksplorasi dan implementasi lukisan Klasik Bali Kamasan dengan media lukis tengkorak kepala kerbau diharapkan dapat memberikan pengayaan visualitas artefak tradisi pada karya-karya seni lukis kontemporer Indonesia.
\end{abstract}

Kata Kunci: Seni Rupa Kontemporer, Tradisi, Media Alternatif, Lukisan Kamasan. 


\section{PENDAHULUAN}

Bali terkenal dengan budayanya yang unik, tradisi dan kehidupan masyarakat sarat akan makna filosophis yang sesuai dengan ajaran Agama Hindu yang dianut masyarakatnya secara dominan. Selain itu, Bali juga memiliki kesenian yang khas dan menjadi kebutuhan vital dalam kehidupan seni budaya masyarakatnya yaitu seni lukis. Lukisan-lukisan ini berkembang pesat di daerah Ubud yang dikenal dengan lukisan wayang gaya Ubud, di Tabanan dikenal lukisan wayang Kerambitan, Denpasar dengan Sanggar Jepun Putih yang menggunakan sampah sebagai bahan untuk melukis, di Badung grup lukisan terdapat di daerah Br. Tanggayuda, Bongkasa, Abiansemal dan di Petang, Buleleng dengan seni lukis kaca dari Nagasepaha, dan lukisan gaya Kamasan. Yang terkenal di Klungkung. Salah satu gaya lukisan tradisi Bali yang akan dikembangkan dan dikaji dalam penelitian ini adalah lukisan Wayang Kamasan. Disebut Lukisan Wayang Kamasan, karena hanya dikembangkan di desa Kamasan, Kabupaten Klungkung.

Seni Lukis Wayang Kamasan (SLWK) merupakan karya seni tradisi yang tumbuh dan berkembang sangat subur di Desa Kamasan, Klungkung. SLWK memiliki identitas sangat khas dan unik, digunakan sebagai pelengkap sarana ritual agama Hindu. Secara tradisi SLWK sangat terikat oleh pakem, norma, nilai, dan ketentuan-ketentuan yang bersifat mengikat dan baku. Dikerjakan secara kolektif dan komunal dengan menggunakan bahan-bahan dan peralatan yang diambil dari alam dan diolah dengan menggunakan teknik-teknik tradisi. Secara visual estetika SLWK sangat artistik, di dalamnya terkandung nilai-nilai filsafat yang bersifat simbolik yang sering digunakan sebagai pencerahan dan bayangan dalam kehidupan manusia, baik di dunia maupun di akhirat (Mudana, 2015: xiii).

Pemahaman ragam budaya Bali yang kini berkembang tidak dapat dilepaskan dari dinamika sejarah Bali masa lampau. Kesenian Bali bertautan erat dengan upacara agama Hindu yang dianut oleh sebagian besar masyarakat Bali. Semua bentuk kesenin di Bali pada mulanya ada kecenderungan untuk menunjang dan mengabadikan kehidupan upacara keagamaan Hindu di Bali. Begitu pula pada kehidupan seni lukisnya yang juga memiliki andil besar terutama dalam upacaraupacara agama Hindu di tempat-tempat pemujaan yang terdapat di seluruh pelosok daerah Bali. Lukisan dianggap sebagai dasar dan bentuk ekspresi kesenian tinggi di Bali. Karya seni tersebut menjadi artefak yang sangat berharga dalam kehidupan ritual dalam tradisi Bali (Sucitra, 2012:5). Berbagai kesenian yang berkembang di Bali, telah sejak lama mengalami proses akulturasi, beradaptasi terhadap kebutuhan masyarakat dan kebudayaan lain yang singgah dan berkembang di Bali. Perkembangan seni rupanya selalu bersifat dinamis, fleksibel, dan beradaptasi terhadap lingkungan serta persoalan keseharian yang bergejolak di dalam masyaraktnya. Terutama kini berkaitan dengan kuatnya penetrasi pariwisata di Bali dan pengaruh kesenian global. Kesadaran akan perlunya kreasi baru yang berkembang dari peninggalan artefak tradisional khususnya pada seni lukis Bali Klasik Wayang Kamasan akan memperkuat akar budaya yang telah ada sesuai dengan tuntutan zaman dan menyesuaikan kebutuhan estetika masyarakatnya.

Salah satu kesenian klasik tersebut adalah kesenian wayang yang telah mengalami perkembangan pesat bersama kesenian lainnya seperti tari, musik, seni rupa, sastra dan lain 
sebagainya. Wayang lebih dikenal lewat seni pertunjukan memilki semua aspek seni tersebut seperti musik (kerawitan), seni suara (kidung atau kawih) dan seni rupa berupa perwujudan figur- figur wayangnya. Citra wayang selalu tertuju pada pertunjukan bayangan dengan tokoh-tokoh yang berasal dari epos cerita Mahabharata dan Ramayana, demikian juga dengan karakter penokohan dari cerita-cerita rakyat yang ada dalam masyarakat Bali.

Berbicara tentang lukisan, di daerah Klungkung terdapat sebuah bangunan bersejarah peninggalan Kerajaan Klungkung yakni Bale Kertha Gosa. Selain arsitektur bangunan yang indah, keunikan Bale Kertha Gosa terletak di langit-langit Bale yang ditutupi dengan lukisan tradisional bergaya Kamasan. Kamasan adalah sebuah desa di Kecamatan Klungkung yang terkenal dengan kreativitas lukisan wayangnya. Lukisan Kamasan biasanya mengambil epik seperti Ramayana atau Mahabharata sebagai tema lukisan. Kreativitas yang diciptakan dalam karya seni mengandung unsur emosi, sehingga dalam proses pengolahannya bisa lentur atau luwes (Indraguna, 2014).

Untuk mengetahui perkembangan kesenian di desa Kamasan, dapat diamati pada peninggalan artefak sebagai bukti perjalanan kebudayaan di desa tersebut. Berdasarkan bukti arkeologis yang ditemukan seperti tahtatahta batu, menhir, lesung batu, palungan batu, monolith yang berbentuk silinder, batu dakon, lorong-lorong jalan yang dilapisi batu kali, ditemukan tersebar di desa-desa Kamasan dan sekitarnya seperti Tojan, dan Gelgel. Hal ini menandakan bahwa, komunitas di sekitar Kamasan berumur cukup tua, serta menunjukkan juga bahwa ketrampilan teknik tradisi megalithik telah mereka kenal sebelum kedatangan pengaruh Hindu. Ketrampilan para undagi dan ke-pande-an yang berasal dan tradisi megalithik ini telah diturunkan kepada generasi berikutnya (Suprihadi dan Nurdjanti, 2006:41). Lebih lengkapnya penjabaran budaya diungkapkan oleh Kuntowijoyo dalam (Parta, 2010:37):

Budaya adalah sebuah sistem yang mempunyai koherensi. Bentuk-bentuk simbolis yang berupa kata, benda, laku, mite, sastra, lukisan, nyanyian, musik, kepercayaan mempunyai kaitan erat dengan konsep-konsep juga tidak terpisahkan dari sistem sosial, organisasi kenegaraan, dan seluruh perilaku sosial.

Berbagai jenis lukisan tokoh pewayangan sudah dilukis pada kanvas hingga pada titik jenuh, banyak lukisan wayang Kamasan pada kanvas sudah tidak laku dipasaran. Pelukis tidak berani membuat lukisan pada kanvas dalam jumlah banyak, dan hanya membuat lukisan wayang kamasan pada kanvas apabila ada pesanan saja (preorder). Selain itu konsumen biasanya membawa ukuran tersendiri untuk membuat lukisan wayang pada kanvas dengan kata lain lukisan wayang pada kanvas dapat dikustomisasi sesuai kebutuhan konsumen. Jika hanya menunggu pesanan konsumen yang tidak jelas kapan datangnya, pelukis akan mengalami penurunan penghasilan. Ketika penghasilan pelukis menurun, secara signifikan berdampak kepada keajegan budaya Bali. Karena pelukis beralih dan mencari sumber penghasilan dari sektor lain, sehingga mulai meninggalkan kegiatan melukis, hal tersebut akan menyebabkan kerajinan lukisan Wayang Kamasan punah (Putra, 2018:22).

Pelukis-pelukis Kamasan biasanya anonim dan merupakan pusat kesenian tradisional Bali yang berhubungan dengan 
pahlawan-pahlawan epos seperti Arjuna, Rama, Abimanyu, dan Hanuman. Fokus dari lukisan mereka terutama lanskap pemandangan atau episode yang membawakan pesan-pesan orang suci, keberanian, kekuatan, peperangan, pembaktian diri dan kebijaksanaan yang banyak terdapat dalam Mahabharata dan Ramayana. Fungsi dari seni lukis pada waktu itu terutama untuk kepentingan adat, pura dan puri. Seni lukis dipersembahkan untuk hiasan pura, ritual agama, balai adat, serta untuk menghias tempat tinggal raja dan punggawa. Tema lukisan dari cuplikan epos Ramayana, Mahabrata, cerita legenda setempat seperti Malat Panji, Cupak Grantang, Calonarang serta sejumlah cerita tantri lainnya. Pelukis termasyur yang melukis dengan gaya klasik adalah Nyoman Mandra dari Kamasan.

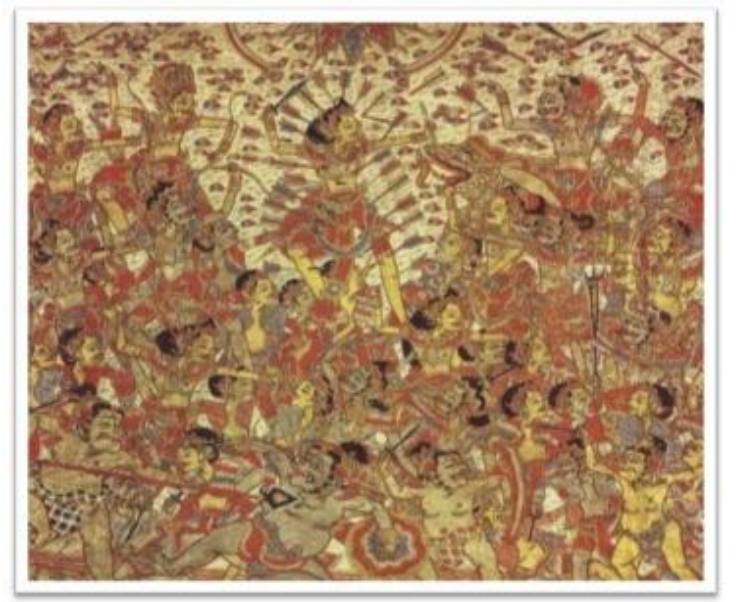

Gambar 1. Lukisan gaya Kamasan, "Kematian Abimayu", akhir abad ke-19, bahan tradisional, 100×106 cm.

Ketertarikan pada ornamentik, karakter bentuk, dan kandungan filosofis dari lukisan Klasik Kamasan mendorong penulis untuk mengenal nilai maknawinya dan varian eksplorasi visualitasnya. Salah satu point penting dalam medan wacana seni rupa kontemporer Indonesia, yakni ruang kemunculan adaptasi estetik artefak seni tradisi berikut nilai lokalitasnya menjadi dialektika seni yang berkembang pesat dan menjadi penanda identitas. Sejalan dengan hal di atas disampaikan oleh Marianto (1994:19) sebagai berikut:

Wacana seni kontemporer internasional yang gemanya terasa juga di Indonesia dewasa ini banyak diwarnai oleh karya-karya 'instalatif', 'indigeneous art' dan 'site specific art' yang dapat dikatakan trendy. Peta seni kini berubah secara radikal. Pemikiranpemikiran yang dulunya seolah melecehkan karya-karya tradisonal dan indigeneuos (asli) kehilangan dasar pijaknya. Ini sejalan dengan berhasilnya terobosan ideologi-ideologi postmodernisme dan postkolonialisme yang tengah marak pula. Pengkotakan seni yang statis atau kaku akhirnya ditinjau kembali karena memang fenomena seni yang berlangsung dewasa ini telah keluar dari dan/atau menembusi kapling-kapling definisi yang telah berpola secara baku.

Pelestarian bukan berarti meniru, tetapi yang dituntut jiwa yang dinamis sesuai dengan perkembangan zaman. Dalam pembuatan suatu karya dibutuhkan suatu kreativitas dan kesadaran akan nilai-nilai lokalitas, elemen visual tradisional serta konsep yang terkandung didalamnya. Dari penjabaran latar belakang tersebut di atas, dapat diamati bahwa artefak dalam kebudayaan tradisi memiliki kandungan makna yang dalam dan telah mengalami proses perenungan yang dalam untuk menangkap berbagai penampakan duniawi dan spiritual melalui perlambang maupun simbol. Pada dasarnya semua karya seni yang diciptakan itu mengandung banyak perlambang. Setiap karya seni merupakan sistem simbol-simbol (Sedyawati, 1991:13). Simbol-simbol elemen tradisi beserta makna yang terkandung didalamnya akan berperan 
penting dalam analisa kebentukan karya penulis.

Mengacu pada hal tersebut, karya ciptaan penulis nanti akan melakukan eksplorasi media alternatif seni rupa berkaitan implementasi unsur visual lukisan klasik Kamasan yang tidak menggunakan material dasar landasan lukisan yang standar yakni kain kanvas melainkan menggunakan media objek tiga dimensi organik yakni tengkorak kepala kerbau. Binatang kerbau merupakan satu genus dengan sapi sehingga dalam beberapa kegiatan suci Hindu Bali banyak menggunakan kerbau sebagai perantara religi atau kurban suci. Selain itu, keunikan dan kekhasan karakter tengkorak kepala kerbau sangat menarik dijadikan media karya seni, baik sebagai media patung, seni instalasi maupun lukisan. Beberapa varian pola visualisasi lukisan klasik Kamasan yang telah beredar di pasaran yakni yang diterapkan dibidang bulat telur, kipas tangan berbahan kayu, penutup hiasan lampu, namun belum ada yang menerapkannya dibidang keras tengkorak kepala kerbau.

Ekspolorasi tengkorak kerbau telah banyak sebetulnya dilakukan oleh perupa, variasinya bermacam-macam; menggambar desain sederhana berupa garis-garis, titik-titik, atau garis-garis yang sesuai, sementara yang lain melukis seluruh lanskap maupun pola-pola tertentu yang ornamentik pada tengkorak kerbau atau rusa. Disisi lain, kreativitas pelukisan dengan mengangkat nilai-nilai tradisi serta narasi lokalitasnya sebagai konsepsi penciptaan karya seni kontemporer, salah satunya dengan representasi pewayangan jarang dilakukan. Berdasarkan latar belakang di atas maka rumusan penciptaan penelitiaan ini yakni: 1) apa simbolisasi yang menarik pada figur lukisan wayang klasik Kamasan, 2) bagaimana penerapan visualitas lukisan klasik wayang Kamasan di atas bidang tengkorak kepala kerbau menjadi sebuah karya seni yang memiliki kebaruan pada sisi eksplorasi/eksperimentasi medianya.

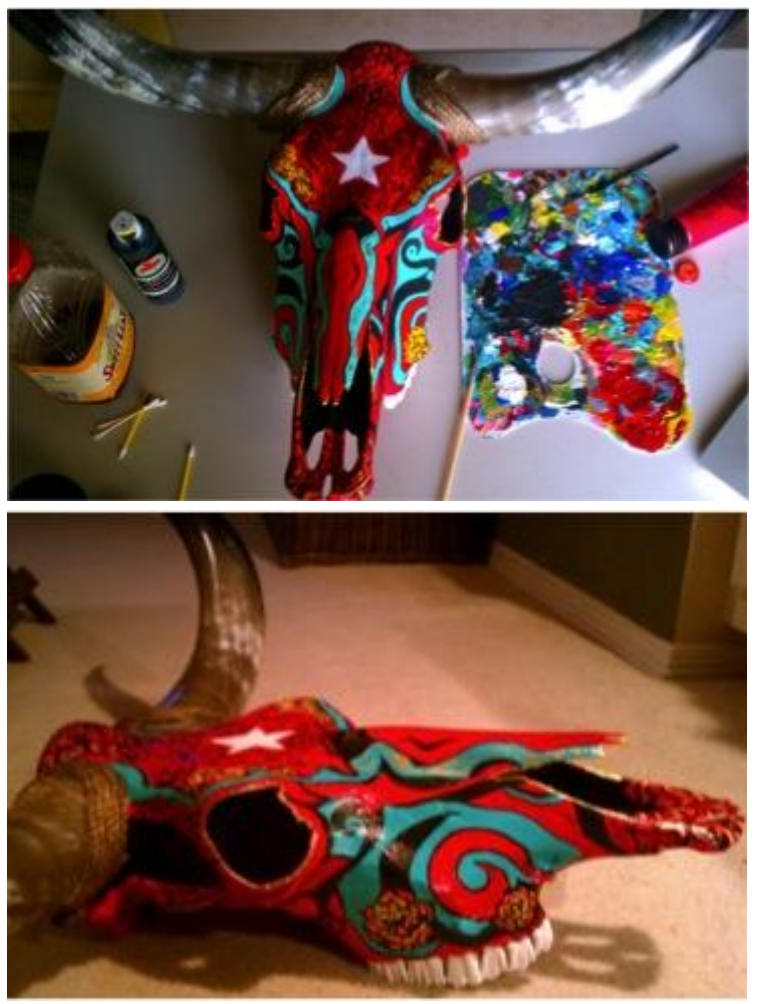

Gambar 2. Tengkorak kepala binatang (kerbau dan rusa) yang telah menjadi karya lukisan dengan medium cat akrilik

(Sumber: Kompilasi gambar dari berbagai sumber website internet).

\section{METODE}

Herbert Read dalam The Meaning of Art merumuskan bahwa keindahan adalah kesatuan dari hubungan bentuk yang terdapat di antara pencerapan-pencerapan indrawi. Di sisi lain Djelantik, (2004:14) mengatakan bahwa semua benda atau kesenian mengandung tiga aspek, yakni wujud, bobot atau isi, dan penampilan. Berawal dari perumusan masalah, maka peneltian penciptaan ini bertujuan untuk merealisasikan gagasan estetik mengenai eksplorasi potensi artistik dari kolaburasi seni lukis 
klasik/tradisional wayang Kamasan dengan elemen material bekas tiga dimensional organic yakni tengkorak kepala kerbau yang kemudian diekspresikan dalam wujud pengembangan teknik dan bahan melalui seni lukis.

Seni lukis dekoratif adalah seni lukis yang bentuk/objeknya didominasi oleh unsur hias serta mengutamakan garis sebagai unsur pembentuknya. Sejalan dengan pengertian seni lukis dekoratif tersebut, Miguel Covarrubias menyebutkan bahwa seni lukis Bali adalah: ...."intricate and assentially decorative" (rumit berbelit-belit dan pada dasarnya dekoratif) (Covarrubias, 1981:180). Pada dasarnya seni lukis merupakan pengungkapan pengalaman artistik yang divisualisasikan dengan menggunakan garis dan warna sedemikian rupa sehingga mencapai harmoni. Seperti yang dikemukaan oleh Read (1975:2) bahwa:

"seni lukis: adalah penggunaan garis, warna, tekstur, ruang dan bentuk (shape), pada suatu permukaan, yang bertujuan menciptakan image-image. Image-image bisa merupakan pengekspresian dari ide-ide, emosiemosi, pengalaman-pengalaman, yang dibentuk sedemikian rupa sehingga mencapai harmoni".

Sebagai suatu karya yang dibentuk dari elemen-elemen tertentu maka suatu lukisan adalah merupakan suatu struktur dan susunan. Sesuai dengan pendapat Herbert Read di atas bahwa seni lukis terdiri dari elemen-elemen garis, warna, tekstur, ruang dan bentuk. Unsurunsur itu dibentuk dalam suatu susunan yang merupakan ekspresi atau curahan ide pengalaman-pengalaman serta emosi pelukis. Penyusunan tersebut dikatakan berhasil apabila terbentuk suatu keselarasan atau harmoni, yaitu apabila dalam penyusunan tersebut memenuhi prinsip-prinsip pengorganisasian.
Adapun prinsip tersebut adalah adanya unity (kesatuan), ritme (irama), balans (keseimbangan) dan proporsi (perbandingan ukuran).

Dalam metode penciptaan dalam seni rupa, Marx berkata bahwa, betapa seni tidak hanya mimetik dengan maksud utilatarian secara langsung tetapi selalu ada unsur-unsur dalam karya seni yang memiliki tujuan di dalam dirinya sendiri, di mana proses kreatif tidak lain adalah manusia yang beraktivitas dan bermain. Sementara John Stuart Mill seorang filsuf Inggris berpendapat bahwa, budaya, intelektual, atau kesenangan spiritual memiliki arti lebih mendalam dari sekadar kenikmatan fisik (Nuning W., 2015:24).

Objek material penciptaan lukisan ini akan mengembangkan unsur dekoratif dari lukisan tradisi klasik Bali Kamasan. Ketertarikan pada ornamentik, karakter bentuk, dan kandungan filosofis dari lukisan Klasik Kamasan secara keseluruhan dapatlah dikatakan mempunyai corak yang sepenuhnya dekoratif berdasarkan keaslian dari pola pewayangan Bali. Tentang pengertian dekoratif dalam seni lukis, disebutkan oleh Kusnadi adalah: "seni lukis yang menstilir segala bentuknya menjadi elemen hiss dengan memberi warna sebagai unsur hias" (Kusnadi, 1976:43). Selanjutnya Sanento Yuliman men jelaskan seni lukis dekoratif sebagai berikut:

Kecenderungan kepada gaya hias (dekoratif) dalam seni lukis ini, kita dapat mengenali objek daun dan pohon, tetapi bentuknya dipolakan, digayakan. Ciri gaya ini ialah garis atau watak kegaris-garisan (karena tiap bentuk dirumuskan dengan garis yang jelas). Irama tetap berulang karena pengulangan atau penjajaran bentuk telah berpola serta susunan yang tertib serta teratur (Yuliman, 1976:23). 
Ada beberapa model atau strategi pengembangan ragam hias yang dilakukan oleh perupa dalam beradaptasi terhadap perkembangan globalisasi. Model Pengembangan Ragam Hias secara Intrinsik. Strategi ini adalah lebih mengedepankan bagaimana ragam hias yang tercipta tersebut distilasi, ditransformasi, didistorsi maupun dideformasi pada unsur-unsur rupa ragam hias tersebut agar mampu menampilkan gaya yang lebih indah. Pertama, ragam hias didesain dengan mempertimbangkan prinsip formalistik yaitu kesederhanaan, keselarasan, irama, kesatuan, keharmonisan yang terpadu menjadi satu kesatuan produk yang indah estetik, dan fungsional, serta mampu mencerminakan nilai rasa atau taste secara ekslusif. Model kedua adalah mencoba mengembangkan ragam hias dengan kekuatan ekstrinsik yaitu nilai makna atau simbolis. Model kedua ini lebih mengedepankan makna atau nilai simbolis sebagai variabel utama dalam penciptaan sebuah ragam hias. Model ketiga adalah mencoba meniru karya yang lagi ngetrend. Dalam rangka menyesuaikan dinamika pasar maka perajin terkadang mengembangkan ragam hias dengan mengadopsi bentuk-bentuk yang lagi ngetrend di pasar tanpa mengkaitkan atau mengkorelasikan dengan unsur-unsur ragam hias tradisional (Haryanto, 2013:31).

\section{HASIL DAN PEMBAHASAN \\ Pembahasan Capaian Penciptaan}

Pemahaman berkesenian dalam masyarakat Bali berbeda dengan berkesenian dalam pengertian modern. Tidak ada istilah seni dan seniman. Aktivitas mereka melebur dalam upacara ritual masyarakatnya yang didasari oleh agama Hindu. Segala bentuk kesenian selalu mengacu pada kepentingan agama, didasari oleh kebersamaan dalam tata aturan adat istiadat. Penulis memiliki ketertarikan atas dinamika transformasi seni rupa tradisi Bali yang bersentuhan dengan wacana-wacana seni rupa kontemporer. Terkait dengan penelitian terapan ini pemahaman atas kedalaman filosofi, sejarah, estetika hingga perkembangan terkini dalam medan seni rupa Indonesia mutlak diketahui sehingga karya seni yang dihasilkan tidak hanya berdasarkan keindahan tampilan rupa tapi juga kedalaman gagasan dan makna simbolik. Demikian juga terhadap perkembangan seni rupa tradisi Bali tidak bisa terlepaskan dari tarikan dan tegangan pengaruh seni rupa nasional dan global.

Perkembangan seni rupa Indonesia kini melaju bersama perkembangan seni rupa lain yang dihasilkan berbagai masyarakat di dunia. Perkembangan ini disebut seni rupa kontemporer yang dianggap sebagai sebagai cermin perkembangan dan perubahan masyarakat kontemporer yang bersifat global. Nugroho \& Himawan (2014:100) mengutip pernyataan peneliti seni rupa kebangsaan Australia, Turner (1993), menyimpulkan bahwa:

"Today's contemporary art is a product of tradition, historical cultural encounters, the confrontation with the West in more modern times, and the recent economic, technological and information changes which has pushed the world towards a 'global' culture and greatly accelerated those interactions".

Penjelasan Turner ini bisa dipahami sudah melampaui anggapan tradisional seni yang memahami bahwa ekspresi seni hanyalah bagian dari tradisi hidup dan masa lalu suatu masyarakat. Perkembangan seni rupa kontemporer, dalam pemahaman dan praktiknya, tidak hanya mengandung unsur tradisi saja, tetapi bahkan berkembang lebih 
agresif menjelajahi kemungkinan-kemungkinan pengalaman manusia pada masa mendatang yang didorong oleh interaksi perkembangan ekonomi dan perkembangan teknologi informasi yang bersifat global. Terlebih mengenai karya-karya kontemporer yang memiliki karakter mengambil visualisasi masa lalu dan masa kini dalam wacana sosial budaya (Nugroho \& Himawan, 2014:100).

Oleh karena beragamnya media dan jenis karya seni dalam perkembangan seni rupa kontemporer, proses pendataan terhadap karya-karya kontemporer yang menampilkan visual tradisi tidak digolongkan dalam bentuk, jenis, dan media, tetapi karya-karya tersebut dapat digolongkan pada beberapa golongan awal karya yang mengambil visual tradisi sebagai tema, sebagai berikut: (1) Kelompok karya yang secara lugas menampilkan artefak, visualisasi tradisi tanpa melakukan perubahan terhadap bentuk representasi awal; (2) Kelompok karya yang melakukan deformasi bentuk terhadap representasi awal visualisasi tradisi (Nugroho \& Himawan, 2014:100).

Ketertarikan penulis pada ornamentik, karakter bentuk, dan kandungan filosofis dari lukisan Klasik Wayang Kamasan memang mendorong untuk menyelidiki dan mengeksplorasinya lebih jauh. Terutamanya dalam perkembangan seni rupa kontemporer Indonesia, kekayaan artefak seni tradisi berikut nilai lokalitasnya menjadi pergulatan wacana seni rupa kontemporer. Visualisasi tradisi ini seringkali muncul pada karya-karya kontemporer dalam bentuk tanda-tanda ataupun penanda yang mengkaitkannya pada pola-pola visualisasi pada karya-karya tradisi seperti batik, lukisan wayang, dan tarian. Yudoseputro (1991:31-48) cenderung mengategorikan seni rupa klasik (tradisi) pada perkembangan seni yang bercorak Hindu-
Budha hingga perkembangan abad Islam di Indonesia.

Bale Kertha Gosa merupakan sebuah bangunan peninggalan kerajaan Klungkung yang sampai sekarang keberadaan bangunan ini masih tetap dilestarikan. Bale Kertha Gosa ini memiliki suatu keunikan tersendiri yang terdapat di langit-langit bangunannya yang dihiasi oleh lukisan tradisional khas kamasan, lukisan di bangunan Bale Kertha Gosa ini menggambarkan filosofi Hindu yang penuh dengan ajaran moral. Lukisan di langit-langit Bale Kertha Gosa dulunya dipergunakan oleh raja-raja pada saat mengadili seseorang di Bale Kertha Gosa tersebut. Setiap orang atau terdakwa yang diadili di Bale Kertha Gosa akan di berikan keputusan dan ceritra-ceritra pendidikan moral terkait dengan apa yang di gambarkan di lukisan langit-langit Bale Kertha Gosa.

Lukisan di langit-langit Bale Kertha Gosa ini terbagai menjadi sembilan (9) petak dan di setiap petaknya memiliki alur cerita yang berbeda-beda. Lukisan wayang yang ada di plafon bangunan Bale Kertha Gosa dikerjakan oleh seniman dari Kamasan (Klungkung) yang dipimpin oleh I Gede Modara untuk membuat lukisan dengan motif wayang. Adapun cerita lukisan wayang yang dipaparkan pada langitlangit bangunan Bale Kertha Gosa menceritakan tentang cerita Tantri Kandaka, Bhima swarga, Garuda mencari amerta, Pelelindong dan lain sebagainya. Sebelumnya lukisan di langit-langit Bale Kerta Gosa dibuat pada kain, namun pada tahun 1930 dipugar dan dicat pada eternit.

Penelitian terapan ini berupaya untuk secara kreatif menemukan potensi alternatif kreativitas yang berbeda dari pola standar pelukisan wayang Kamasan dari yang telah disebutkan di atas. Dinamika perkembangan 
kebudayaan membuka pintu seluasnya selain bersifat konservatif, menjaga dan memelihara, namun juga berpeluang untuk mengolah, merubah, memperkaya maupun proses transformasi karya seni sesuai dengan perkembangan zaman. Dalam penciptaan karya seni, persoalan material medium yang digunakan juga bisa mendatangkan cara pandang yang berbeda serta teknik yang lebih spesifik, artinya dia bisa keluar dari pakem kebiasaan pola melukis, dan menemukan metode penciptaan yang lebih personal. Salah satu kreativitas yang penulis kembangangkan dalam memperkaya kebentukan dan estetika seni lukis wayang Kamasan adalah dengan media lukisan alternatif yakni tulang tengkorak hewan (kerbau).

Tulang merupakan bentuk penyambung yang menyusun mayoritas rangka kebanyakan vertebrata yang terdiri dari komponen organik (sel dan matrik) dan inorganik. Tulang, atau jaringan oseaso, merupakan bentuk kaku jaringan ikat yang membentuk sebagian besar kerangka vertabrata yang lebih tinggi. Jaringan ini terdiri atas sel-sel dan matrik intersel. Matrik mengandung unsur organik yaitu terutama serat-serat kolagen dan unsure anorganik yang merupakan dua pertiga berat tulang. Tulang merupakan suatu jaringan keras yang terdiri dari susunan serabut organik atau kumpulan sel-sel tulang yang diisi dengan matriks berupa zat-zat organik atau mineral, terutama kalsium karbonat dan fosfat. Pada sapi, tulang memiliki berat sekitar 15-20\% dari keseluruhan berat sapi. Menurut asalnya, tulang dapat dibedakan menjadi dua kategori, yaitu:

\section{Collected bone}

\section{Slaughterhouse bone.}

collected bone memiliki ukuran yang bervariasi, banyak mengandung daging dan kadar lemak tinggi. Jenis ini banyak dijumpai di penjual daging di pasar. Slaughterhouse bone dapat diperoleh di tempat pemotongan hewan. Tulang jenis ini mendapat perlakuan sebelum diolah lebih lanjut sehingga sedikit terkontaminasi [Wong, 1989; Ward, 1977 dalam (Prasetyo, 2004/2005:7).

Sida (2019) memaparkan bahwa tulang memiliki beberapa sifat yang sangat unik yang tidak dimiliki oleh benda lainnya diantaranya :

1) Tulang mempunyai sistem kanalikuli, yaitu saluran halus yang meluas dari lakuna ke lakuna lainnya dan meluas ke permukaan tulang, tempatnya bermuara ke dalam celahcelah jaringan. Cairan jaringan dalam celah-celah ini berhubungan langsung dengan cairan di dalam system kanalikuli dan dengan demikian memungkinkan pertukaran metabolit antara darah dan osteosit. Melaui mekanisme ini sel-sel tulang tetap hidup, walaupun dikelilingi substansi intersel yang telah mengapur.

2) Tulang bersifat avaskular. Sistem kanalikuli tidak dapat berfungsi baik bila jaraknya dari suatu kapiler melebihi 0,5 mm. oleh karena itu tulang banyak mengandung kapiler yang terdapat di dalam saluran havers dan saluran volkmann.

3) Tulang hanya dapat tumbuh melalui mekanisme aposisional. Penumbuhan intersial, seperti tulang rawan, tidak mungkin pada tulang karena adanya garam kapur (lime salt) dalam matriks yang tidak memungkinkan terjadinya pengembangan dari dalam.

4) Arsitektur tulang tidak bersifat statis. Tulang dihancurkan setempat-setempat dan dibentuk kembali. Jadi harus selalu dipertimbangkan adanya proses rekontruksi yang berlanjut terus. 
Tulang yang biasanya digunakan sebagai barang kerajinan adalah tulang sapi, tulang kerbau dan tulang ikan. Tulang sapi dan tulang kerbau dipilih sebagai bahan utama bagi pengrajin karena memiliki ukuran yang besar, sedangkan untuk tulang ikan pengrajin memilih jenis ikan tertentu saja yang mana memiliki ukuran tulang besar dan kuat. Sistem perwujudan tulang yang ditemui dilapangan adalah sebagai berikut: 1) tulang-tulang yang dihasilkan di balai potong hewan dibersihkan dari sisa daging yang melekat dengan cara direbus sampai semua dagingnya mengelupas; 2) tulang-tulang yang telah direbus dijemur sampai benar-benar kering kurang-lebih 2-3 hari; 3) tulang-tulang yang sudah kering akan menunjukan warna putih kekuning-kuningan dan siap diproses menjadi barang kerajinan atau karya seni lainnya.

\section{Pembahasan Proses Penciptaan}

Subbab berikut ini akan membahas proses kreatif penciptaan lukisan dari persiapan material tengkorak kepala kerbau; sketsa, mewarnai dasaran/priming, hingga memberi outline bidang objek tokoh pewayangan. Secara konten visual serta muatan filosofisnya yang dihadirkan pada lukisan klasik Bali Wayang Kamasan telah dipaparkan pada bahasan di atas. Penting kiranya membahas bagian perbagian dari proses praktikal penciptaan lukisan, sehingga hasil yang dicapai secara visual dapat dianalisa dan dinikmati oleh publik seni. Setelah pada bagian metode telah diterangkan tiga proses tahapan yang dilalui untuk menjadikan sebuah karya menuju akhir/selesai.

Proses penciptaan pada karya ini tidak seperti umumnya yakni kanvas atau kertas, tapi dimulai dari persiapan bidang permukaan lukisan yakni permukaan tengkorak kerbau yang sebelumnya telah dibersihkan serta diberikan lapisan dasar dengan cara disemprot serta dikuas. Harus dipastikan keseluruhan bagian permukaan tulang tertutup dengan rapi cat putih, sehingga siap untuk dilekatkan cat akrilik. Pada lukisan tradisi klasik Bali, pewarnaan dengan cat air berbahan alami, sedangkan dalam lukisan penulis menggunakan cat air jenis cat akrilik. Salah satu kualitas yang paling menarik dari cat akrilik adalah kemiripannya yang luar biasa (dengan cara memanipulasi perumusan cat, pengencer, dan berbagai jenis adiktif) dengan karakteristik media cat tradisional (Sucitra, 2013: 66).

Berikut proses langkah-langkah penciptaan karya "Implementasi Lukisan Klasik Kamasan pada Media Alternatif Tengkorak Kepala Kerbau". 


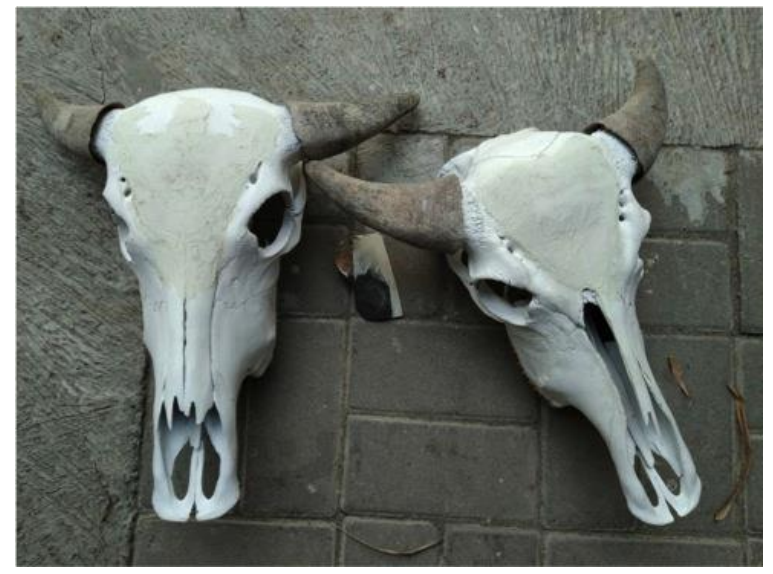

Gambar 3. Permukaan dahi batok kepala kerbau diplamir untuk meratakan bagian belahan tengah agar memudahkan untuk dilukisi dan tidak ada kesan garis pembelah pada sisi tengah kepala kerbau.

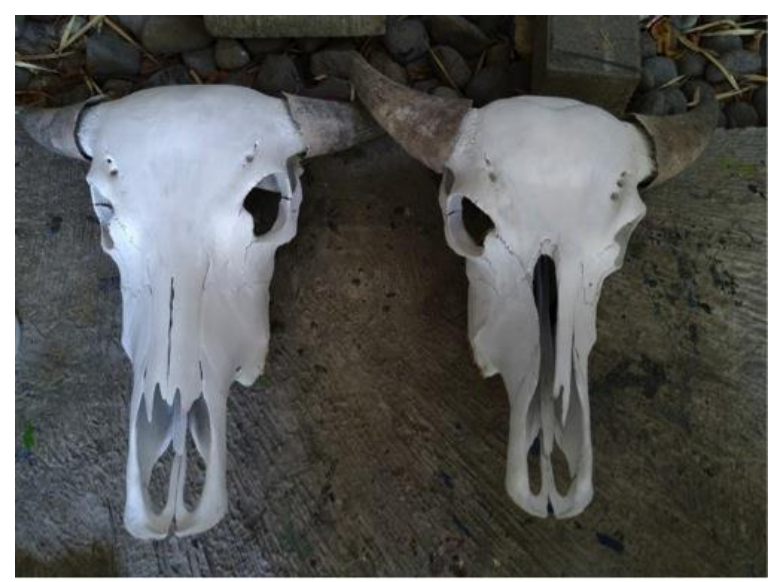

Gambar 4. Permukaan bidang tengkorak kerbau sudah terlapisi dengan baik dan rata dengan dasaran cat akrilik berwarna putih. Pada tahapan ini, bidang lukisan sudah siap dipakai untuk tahapan sketsa.

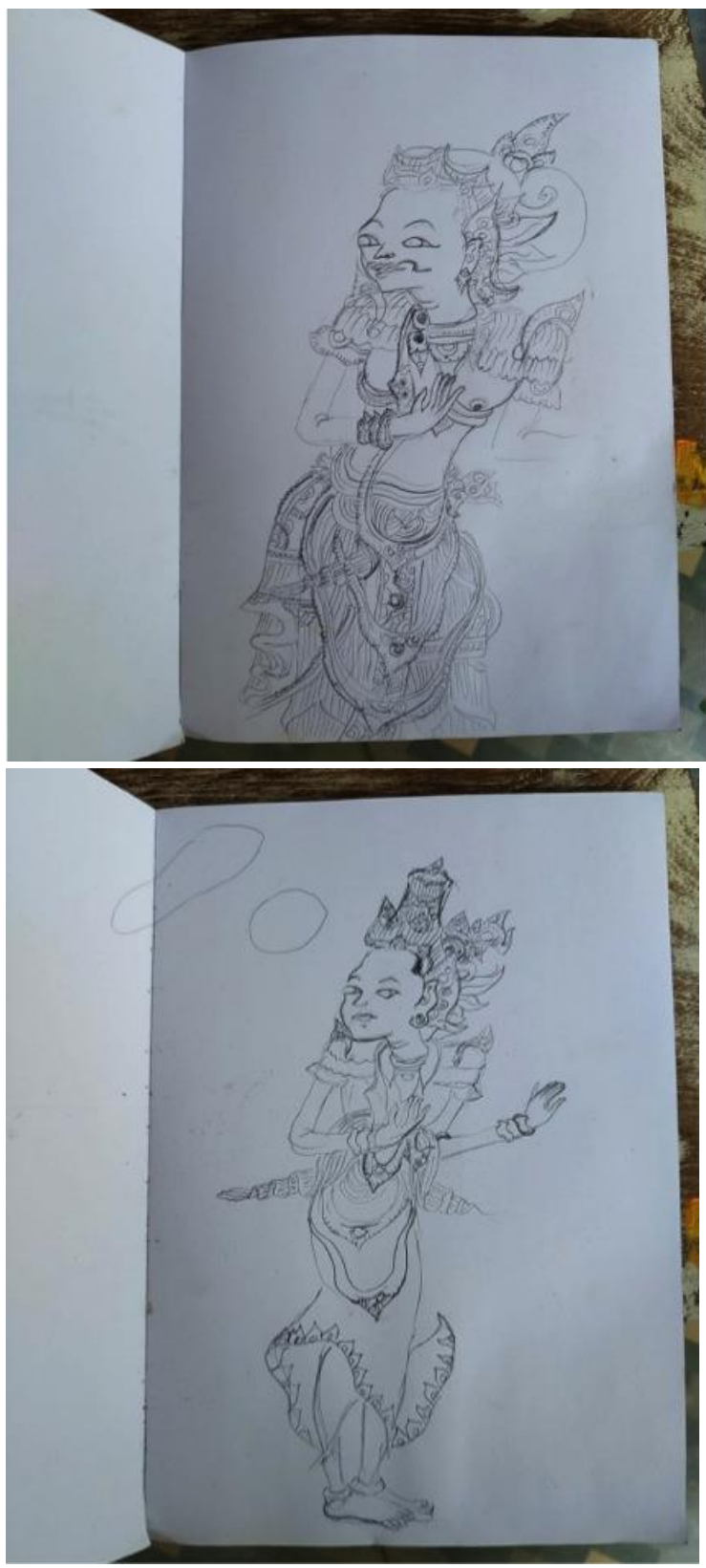

Gambar 5. Lukisan Wayang Kamasan dalam penciptaan karya ini akan mengambil bagian cerita epos Ramayana, tentang kisah filsafat percintaan Rama-Sita hingga peperangan dengan Rahwana yang dibantu oleh pimpinan pasukan kera yakni Hanoman. Sebelum berbagai objek tersebut diterapkan ke atas bidang tengkorak kerbau, maka akan dilakukan studi sketsa untuk mendapatkan gerak, posisi dan komposisi yang harmonis dan presisi untuk bidang bervolume tengkorak kerbau. Berikut adalah studi sketsa beberapa tokoh pewayangan dalam lakon cerita Ramayana. 

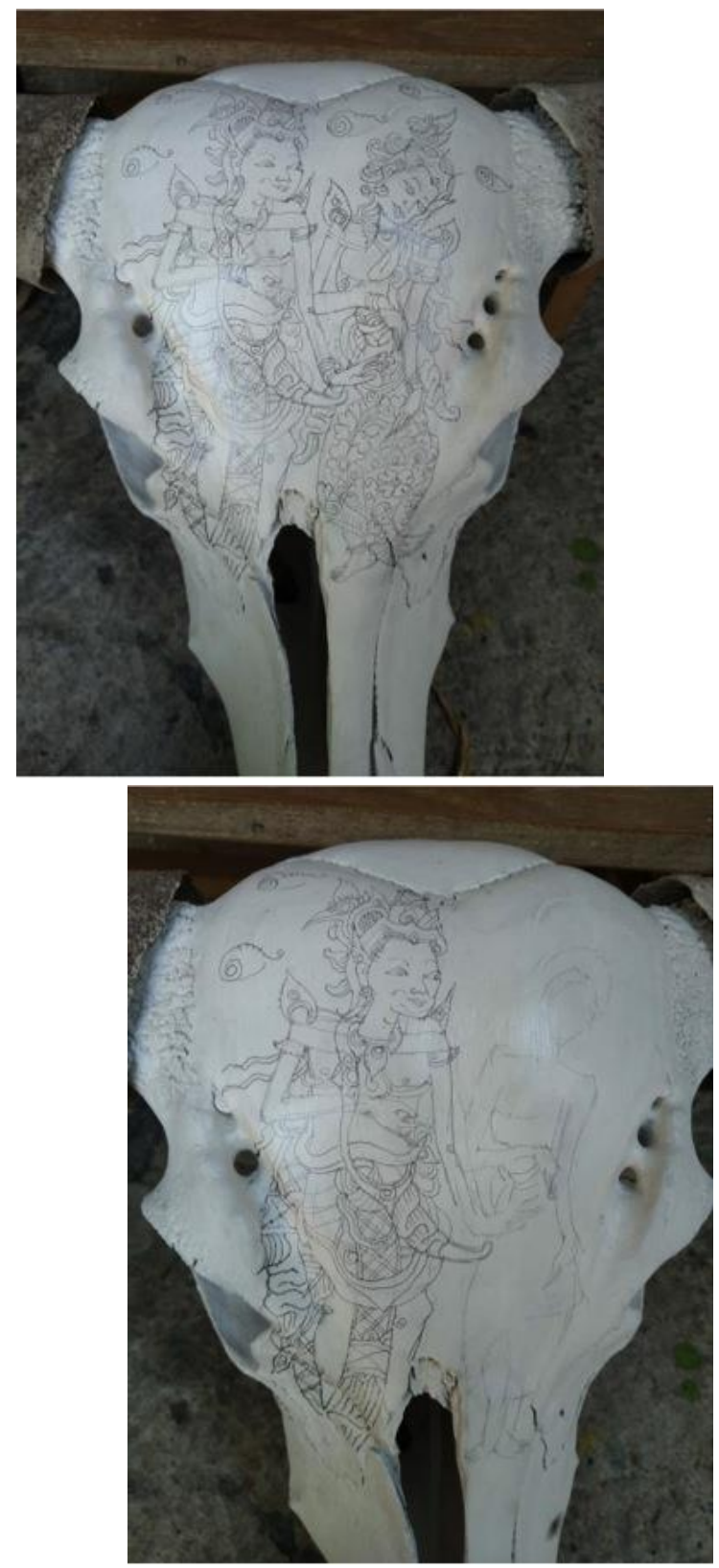

Gambar 6. Aplikasi sketsa pensil diatas bidang tengkorak dengan tokoh Rama Sita yang dikomposisikan pada sisi tengah sebagai titik central dari keseluruhan bidang lukis. Lukisan ini mengambil bagian cerita ketika Rama dan Sita bertapa ke hutan, dan Sita tertarik dengan seekor kijang yang berlarii kesana-sini di dekat pondokan Sita. Lalu Sita meminta Rama untuk menangkap Kijang tersebut untuknya. Ornamentik awan ditempatkan pada sisi latar kedua figur yang memenuhi bagian kening hingga belakang kepala. Untuk objek ornamentik tanaman dan kijang diletakkan pada sisi kanan kiri rahang tengkorak.
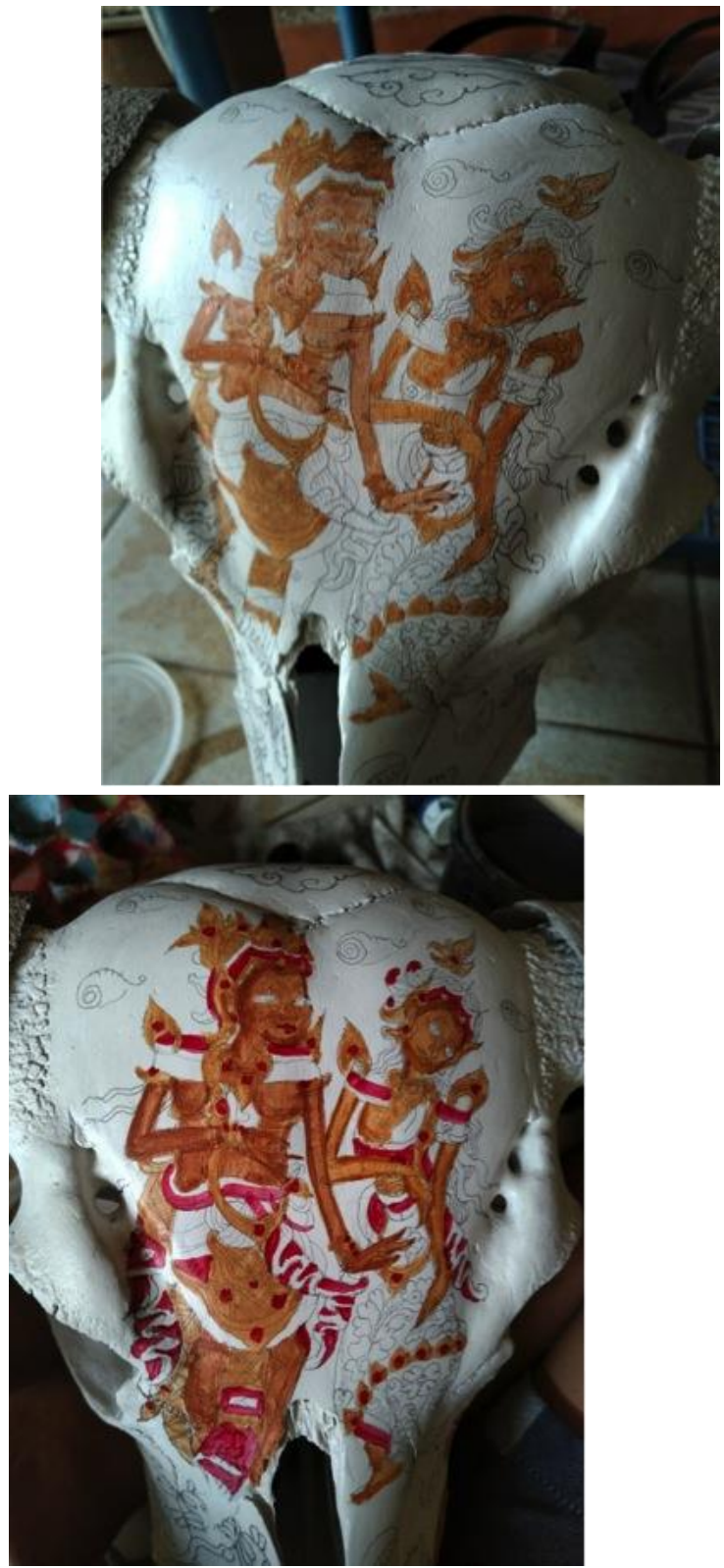

Gambar 7. Tahapan berikutnya yakni mewarnai dengan teknik cat air yakni wet on dry, artinya mengoleskan cat diatas permukaan bidang yang kering. Tekniknya transparan, cat dasar dioleskan secara tipis merata dan diulangi dua kali lapisan agar mendapatkan kesan rata warna yang tepat dan memenuhi bidang sketsa. Dimulai dengan warna kulit yakni perpaduan coklat burn siena dengan kuning ocre, sedikit campuran warna putih. Pola mewarnai lukisan Kamasan dengan tipis bertahap dan pelan-pelan, serta secara teratur penumpukan cat dilakukan setelah lapisan cat sebelumnya mengering dengan sempurna. 

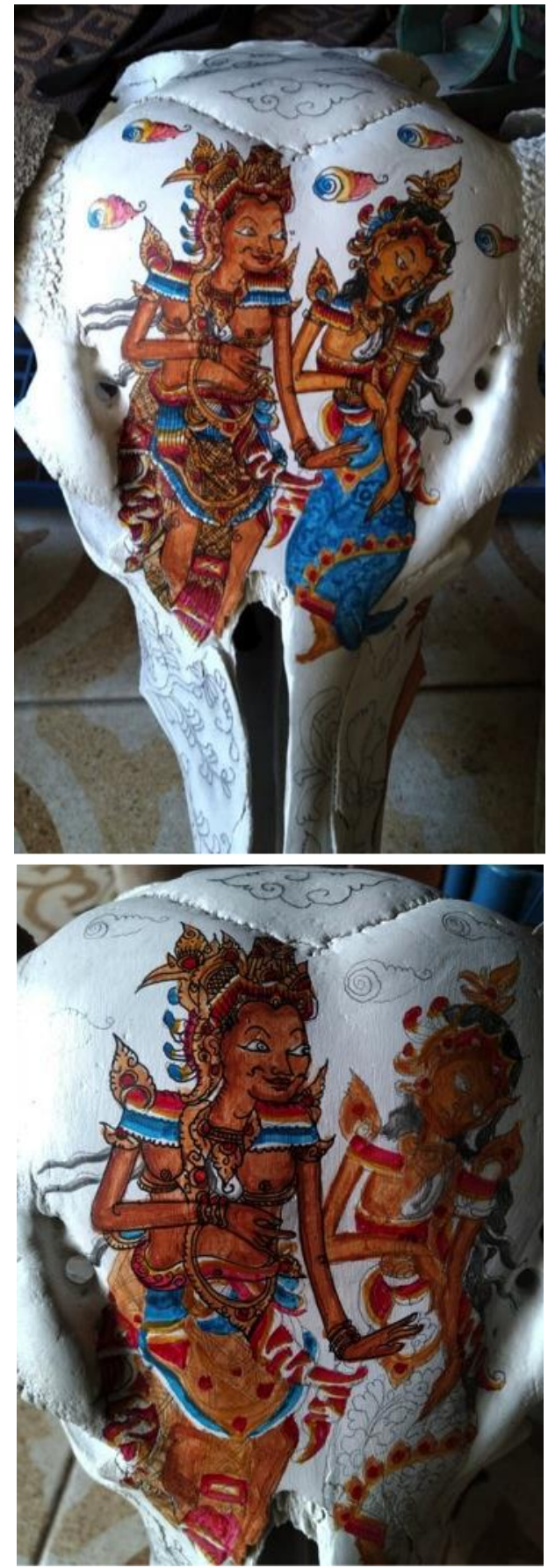

Gambar 8. Kecenderungan warna yang digunakan dalam lukisan kamasan adalah warna-warna primer dan sekunder, yakni merah, kuning, biru, hijau, oranye dan coklat, tentu saja hitam dan putih menjadi komponen utama penguat figur. Pada proses tahapan ini, sudah mulai dilakukan outline objek untuk memperkuat unsur kebentukan ornamentik dan juga detail.

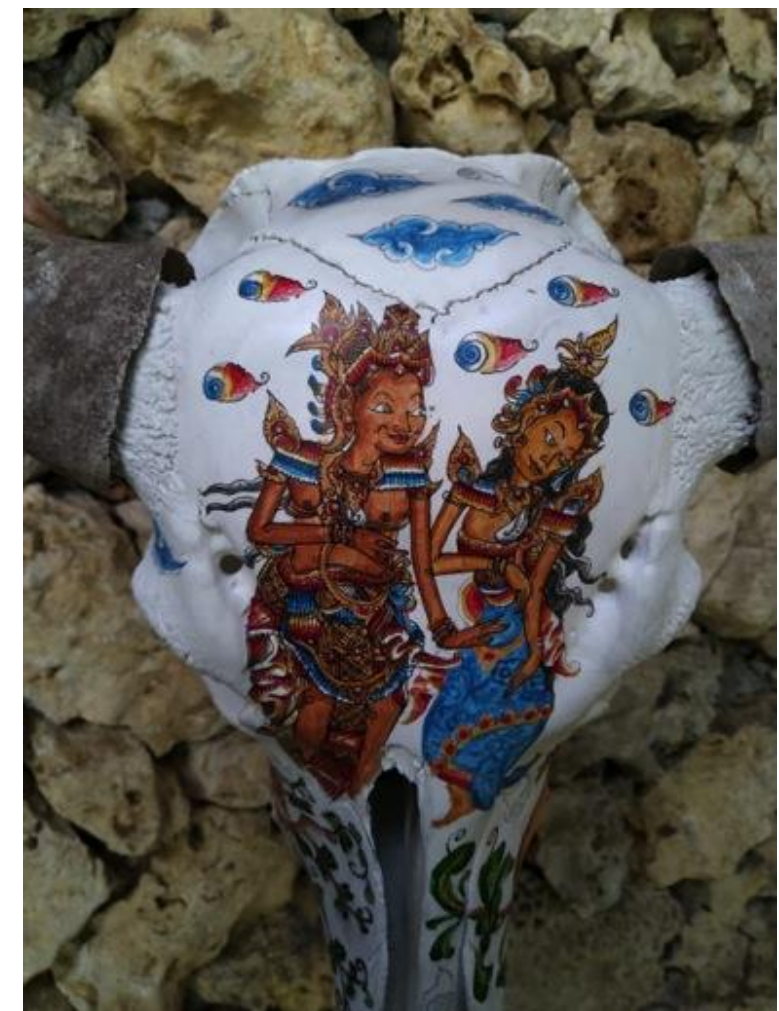

Gambar 9. Daya tarik yang muncul dari pemanfaatan tengkorak kerbau sebagai bidang lukisan adalah kita memiliki keluasan dalam membangun dimensi cerita dengan peletakan objek yang tepat sehingga seakan-akan terjadi perspektif. Seperti yang tampak dalam proses di atas, penulis meletakan kijang dengan posisi di bawah dan agak ke dalam sehingga kesannya ada komunikasi antara tatapan Sita dan juga kijang. Ditambahkan juga barisan awan-awan tradisi baik yang berwarna biru cerah maupun yang variasi biru, kuning, dan merah. 


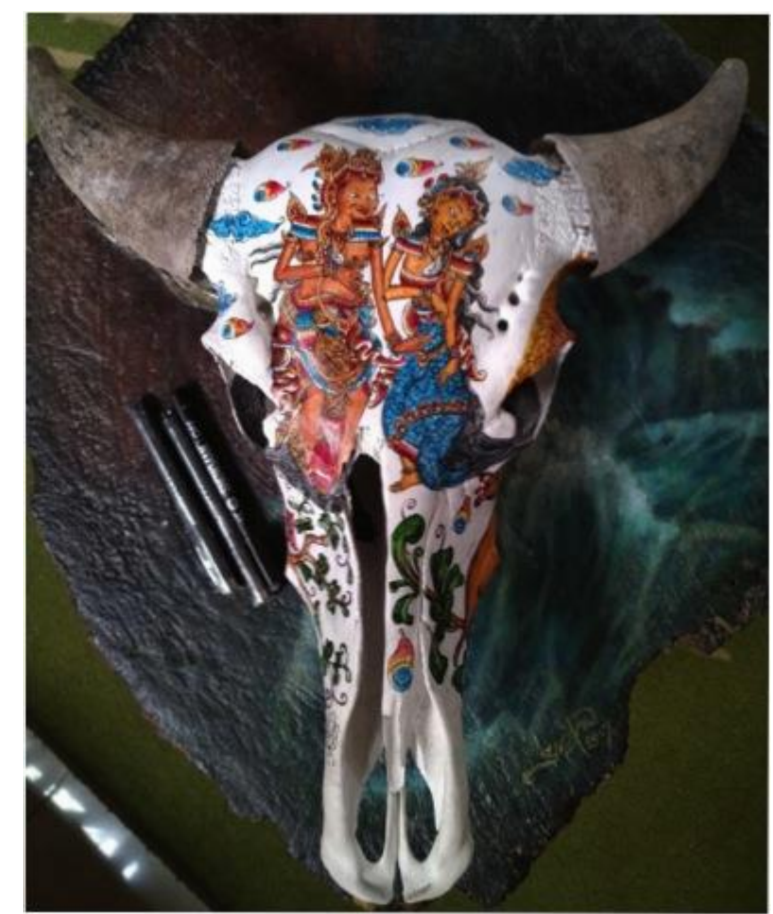

Gambar 10. Tahapan akhir dari pelukisan wayang Kamasan di atas kepala tengkorak kerbau; bidang gambar dibiarkan tetap lapang dengan dasar putih untuk menghadirkan keluasan dan juga daya tarik yang lebih detail dari objek lukisan. Harmonisasi keseluruhan objek-objek figur dilakukan dengan memberikan sentuhan outline hitam dengan drawing pen yang waterproof, sehingga akan tahan lama dan tidak luntur terkena air. Tahapan akhir, sebagai bagian perlindungan bahan-bahan lukisan yakni finishing melapisi permukaan lukisan dengan cairan varnish.

\section{PENUTUP}

Perkembangan medan seni rupa kontemporer global, membuka ruang wacana kolaburasi estetik artefak seni tradisi berikut nilai lokalitasnya dengan berbagai disiplin penciptaan deni serta media baru (media alternatif). Visualisasi tradisi ini seringkali muncul pada karya-karya kontemporer dalam bentuk representasi tanda-tanda maupun simbolisasi berkaitan pada pola-pola visualisasi pada karya-karya tradisi yang diadaptasikan secara transformartif maupun bersifat multikultur. Kesenian Bali yang bersifat multikultur telah melalui proses yang panjang dalam dialektika potensi lokalitasnya terhadap pengaruh modern dari luar yang kelak muncul visualitas unik dan khas di tangan terampil senimannya.

Potensi pengembangan ragam visual seni tradisi dengan pengolahan eksprimentasi media dan bahan, memberi penafsiran baru atas cara pandang elemen ornamentasi tradisi tersebut. Tujuannya jelas, eksplorasi dan implementasi lukisan Klasik Bali Kamasan dengan media lukis tengkorak kepala kerbau diharapkan dapat memberikan pengayaan visualitas artefak tradisi pada karya-karya seni lukis kontemporer Indonesia, temuan variasi ragam media lukis, serta menumbuhkan jiwa 'curiosity dalam kreativitas seni' untuk selalu 'gelisah' menyelami jiwa zamannya. Kajian visual dan aspek simbolis yang dihadirkan melalui pemilihan fragment cerita Ramayana, melalui representasi visual pewayangan didasari atas prinsip bahwa kemunculan karya seni rupa tradisi dalam seni rupa posmodern (kontemporer) merupakan bagian dari dinamika dan konsep berkembang budaya visual.

Selain unsur-unsur tradisi yang tampil pada karya, penting juga dikenali bagaimana unsur-unsur media dan bahan modern, serta prinsip penciptaan seni modern seperti otonomi, kebebasan, dan progresitivitas menjadi elemen yang penting dalam proses kreatif berkarya. Dengan demikian diharapkan implementasi ide dalam kreativitas mengolah kekuatan nilai tradisi dan unsur representasi artefaknya dalam karya-karya kontemporer di era globalisasi dapat dibaca sebagai bagian keberagaman tradisi, serta penguatan identitas budaya bangsa di era kesenian dunia yang menganut universalisme.

\section{DAFTAR PUSTAKA}

Covarrubias, M. (1981). Island of Bali. Kualalumpur: Oxford University Press.

Djelantik, A. A. M. (2004). Estetika: Sebuah 
Pengantar. Bandung: Masyarakat Seni Pertunjukan Indonesia.

Haryanto, E. (2013). "Strategi Pengembangan Desain Kriya (Ragam Hias) dalam Perspektif Potensi Lokalitas." Corak Jurnal Seni Kriya, 2(1, November-April).

Indraguna, K. E. (2014). "Lukisan Gaya Kamasan di Bale Kertha Gosa Semarapura, Klungkung, Bali (Analisis Nilai-Nilai Pendidikan Karakter dan Implementasinya dalam Pembelajaran Sejarah di SMA Berbasis Kurikulum 2013)." Artikel Penelitian, Jurusan Pendidikan Sejarah Fakultas IImu Sosial Universitas Ganesha Singaraja.

Kusnadi. (1976). Warna Budaya. Jakarta: Departemen Pendidikan dan Kebudayaan Republik Indonesia.

Marianto, M. D. (1994). "Berbagai Fenomena Seni dan Bingkai Pandang Terhadap Seni Kontemporer." Jurnal Pengetahuan Dan Penciptaan Seni SENI, IV(1, Januari).

Mudana, I. W. (2015). Transformasi Seni Lukis Wayang Kamasan Modern di Klungkung di Bali. Universitas Udayana.

Nugroho, B. A. (2014). "Visual Tradisi dalam Karya Seni Lukis Kontemporer sebagai Wujud Artistik Pengaruh Sosial Budaya." Jounal of Urban Society's Arts, 1(2, Oktober).

Nuning W., M. M. (2015). "Metode Penciptaan Bidang Seni Rupa: Praktik Berbasis Penelitian (Practice Based Research) Karya Seni Sebagai Produksi Pengetahuan dan Wacana." Corak Jurnal Seni Kriya, 1(MeiOktober).

Parta, I. W. S. (2010). "Modernisasi dan Transformasi Seni Lukis Bali pada Karya I Gusti Nyoman Lempad." Jurnal Seni Rupa Dan Desain ARS, 9.

Prasetyo, S. S. (n.d.). "Kajian Awal Ekstrasi Kolagen dari Tulang Sapi secara Batch."

Putra, I. G. L. A. R. (2018). "Inovasi Kerajinan Lukisan Wayang Kamasan Klungkung." Majalah Aplikasi Ipteks Ngayah, Volume 9(1, Juli).
Read, H. (1975). Pengertian Seni. Yogyakarta: STSRI "ASRI."

Sedyawati, E. (1991). Seni dalam Masyarakat Indonesia. Jakarta: PT Gramedia.

Sida, I. K. (2019). "Perkembangan Kerajinan Tulang."

Sucitra, I. G. A. (2012). "Pita Maha 'Koalisi' Estetika Seni Lukis Klasik Bali dengan Seni Rupa Modern." Jurnal Seni Rupa Dan Desain ARS, XV(Januari-April).

Sucitra, I. G. A. (2013). Pengetahuan Bahan Lukisan. Yogyakarta: BP ISI Yogyakarta.

Suprihadi. (2006). "Vibrasi Seni Lukis Kamasan di Bali, Indonesia."

Yudoseputro, W. (1991). "Seni Rupa Klasik." In Perjalanan Seni Rupa Indonesia: Dari Jaman Prasejarah Hingga Masa Kini. Bandung: Panitia Pameran Kias 19901991.

Yuliman, S. (1976). Seni Lukis Indonesia Baru: Sebuah Pengantar. Jakarta: Dewan Kesenian Jakarta. 

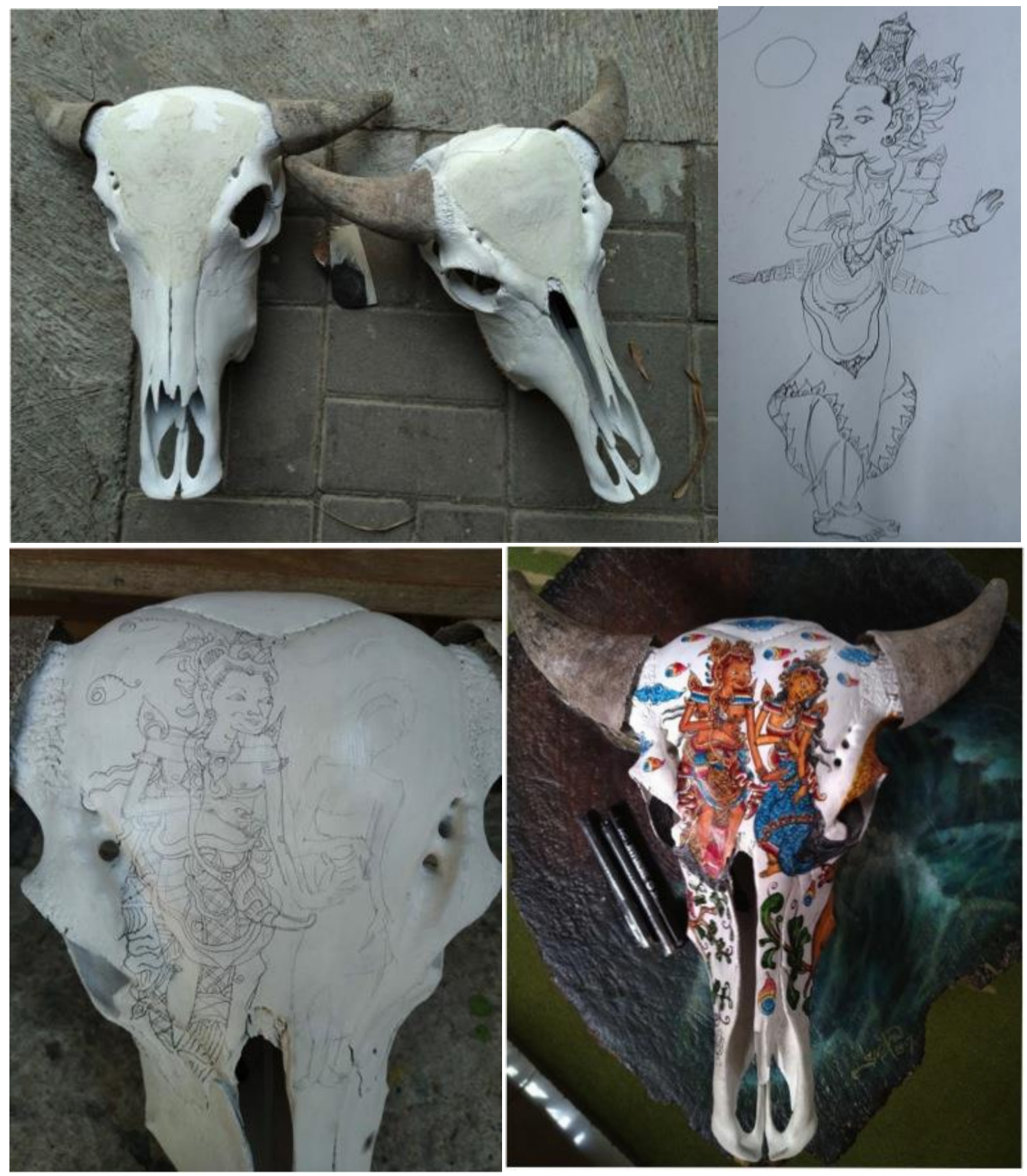